\title{
Ricardo Palma: el gran escritor y los jóvenes del 900
}

\author{
Osmar Gonzales Alvarado \\ Universidad Nacional Mayor de San Marcos \\ osmar.gonzales@gmail.com \\ Lima-Perú
}

\section{Resumen}

En el presente artículo, el autor analiza la obra intelectual de Ricardo Palma identificándolo como una figura que encarna al gran escritor representativo de la nacionalidad peruana. Desde esa ubicación, describe la relación que tuvo con diferentes miembros de la generación del 900, quienes lo reconocieron como su maestro y encarnación del alma nacional. Para ello, el autor utiliza fuentes de primera mano, como las cartas personales, y bibliografía ya conocida.

Palabras clave: Ricardo Palma, Gran escritor, Generación del 900, Tradiciones peruanas

\section{Abstract}

In this article, the author analyzes the intellectual work of Ricardo Palma, identifying him as an intellectual figure that embodies the great representative Peruvian writer. From that location, he describes the relationship he had with different members of the Nine hundred generation, who recognized him as their master and incarnation of the national soul. For this, the author uses firsthand sources, such as personal letters, and known bibliography.

Keywords: Ricardo Palma, Great writer, Generation of 900, Peruvian traditions 
Osmar Gonzales Alvarado (Perú): Doctor en Ciencia Social por El Colegio de México. Es autor de cerca de treinta libros sobre sociología de intelectuales. Colaborador de revistas especializadas del Perú y del extranjero. También es profesor universitario y coordinador de la Maestría de Sociología de la Unidad de Posgrado de Ciencias Sociales de la Universidad Nacional Mayor de San Marcos. Como funcionario ha desempeñado diversos cargos, como agregado cultural a la Embajada del Perú en Argentina, director técnico en dos oportunidades de la Biblioteca Nacional del Perú, director de la Casa Museo José Carlos Mariátegui del Ministerio de Cultura y asesor del Ministerio de Educación en temas de promoción del libro y la lectura, entre otros. Actualmente, es director académico del libro "El Perú en la Emancipación", de la Universidad Ricardo Palma. 
La literatura palmista es tan abundante no solo a nivel nacional sino también internacional, que resulta una labor extremadamente complicada encontrar algún aspecto de la vida y obra de nuestro tradicionista que no haya sido abordado. Por esta razón, modestamente trataré de aportar elementos que nos permitan ahondar en la figura o representación de intelectual que encarna don Ricardo Palma en su contexto y, desde ahí, analizar su relación con la juventud de la llamada generación del 900.

\section{Ricardo Palma, gran escritor}

En la sociología de intelectuales existe una figura de intelectual que se puede aplicar a Ricardo Palma, cual es la de "gran escritor". El literato y estudioso francés Paul Bénichou es quizás el que más se ha dedicado a analizar la ascensión del gran escritor en el contexto de la modernidad. Su muy importante libro titulado La coronación del escritor, 1750-1830 (1981) analiza precisamente cómo el hombre de letras se constituyó en la referencia intelectual fundamental en la Francia de mediados del siglo XVIII y principios del siglo XIX.

Bénichou sostiene que en el proceso cultural e ideológico del Iluminismo, que desembocaría en la Revolución de 1789, el mundo occidental se transformaría radicalmente. La caída del Antiguo Régimen, que se sostenía en su supuesta vinculación con el poder divino, abriría paso al poder legitimado terrenalmente, a la comprensión de que el orden político y social son productos de la propia acción humana, y que los individuos son responsables de sus decisiones y consecuencias, esto es, que la modernidad significa "el advenimiento del poder laico". En este mundo desencantado, como describiera Max Weber al ingreso de la modernidad, es que los escritores acuden para cubrir el papel que el poder celestial había dejado de ocupar. 
Los individuos ya no buscarían respuestas a sus problemas en el firmamento, sino en sus escritores de carne y hueso. Recordemos también que es el momento histórico en el que se empiezan a afirmar las identidades nacionales y a construir sus respectivas organizaciones políticas que son los estados nacionales. En estas novísimas construcciones humanas se glorificaría al gran escritor casi como un nuevo dios, encarnación del inédito "poder espiritual laico".

Para comprender mejor su preeminencia, debemos tomar en cuenta que las diferenciaciones entre la filosofía y la literatura, o entre las distintas disciplinas que daban sus primeros pasos no estaban precisamente establecidas. En tal contexto, el escritor podía opinar sobre cualquier tema que demandara la sociedad, privilegio que sería estimulado por la expansión de la educación y de la cultura escrita, frutos del Iluminismo, lo que ocasionó que cada vez más personas se dedicaran al fomento de las diversas manifestaciones culturales y de las letras creando nuevos géneros, como el ensayo (Montaigne), la literatura erótica (Sade), las reflexiones humanistas (Voltaire), el artículo científico (los enciclopedistas), las novelas de folletín, la literatura satírica, así como permitió la proliferación de diarios y revistas en los que los escritores plasmaban sus ideas, incluso en publicaciones de circulación clandestina (Torres Puga, 2000; Darnton, 2008). Ideas que irían encontrando cada vez mayor número de receptores, de lectores, a los que los literatos que - al mismo tiempo que se afianzaban como personajes de ideas fundamentalescontribuían a dar forma al nuevo sujeto, es decir, al ciudadano. Como menciona Rodríguez Guerrero-Strachan: "Es en el siglo XVIII cuando la idea del intelectual se hace presente como alguien que colabora en la educación del género humano, y es entonces también cuando el grupo social toma conciencia de sí mismo" (2008, p. 51). 
Y algo más, con el poder de la palabra escrita en un contexto de expansión, el gran escritor contribuiría a dar forma a los elementos que distinguirían las específicas formas de ser nacionales, lo que supone una relación de doble vía: el escritor toma de la vida experiencias y formas típicas de comportamientos en los que sus lectores se sienten identificados, al mismo tiempo que adquiere legitimidad como su genuina expresión. Pero para ello, era necesaria una alianza tácita entre el gran escritor y las élites ilustradas que le posibilitara los medios por los cuales podía expandir su influencia, al mismo tiempo que mejorara sus condiciones materiales de vida.

No obstante, el escritor, ya afianzado como el sujeto poseedor del poder de la palabra escrita por medio de la cual podía formar y transmitir ideas o criticarlas, no se sentía parte de la burguesía a pesar de ser burgués: el gran escritor como sujeto desclasado. Paradójicamente, de otra manera no hubiera consolidado su función social como intelectual "puro" (lo que a finales del siglo XIX Julien Benda denominaría clérigos, a propósito del Caso Dreyfus).

No sería provechoso trasladar acríticamente las ideas de Bénichou a la realidad peruana que conoció Ricardo Palma, por esa razón las confronto con la experiencia de nuestro escritor en el Perú de fines del siglo XIX e inicios del XX. Importar las ideas de Bénichou sin comprender la especificidad de la vida peruana devendría un ejercicio improductivo; por eso prefiero dialogar con sus planteamientos y así desbrozar el camino que nos permita calibrar mejor la figura y trascendencia de nuestro tradicionista en tanto encarnación de una figura o representación de intelectual, la del gran escritor.

Siendo Palma miembro de la generación inmediatamente posterior a la conquista de la Independencia (nació el 7 de febrero de 1833), conoció desde niño la anarquía que caracterizó 
a la política peruana, hegemonizada por caudillos militares que vivían en una perpetua guerra civil. En el Perú el proceso de separación de España no significó una revolución como la de 1789 en Francia, pero sí la descomposición y aniquilamiento del orden colonial. El desafío era la construcción de un Estado nacional y la constitución de ciudadanos que dieran sentido y fundamento a la República. En tal contexto, las letras, la literatura, cumplían un papel fundamental.

El aura de prestigio que envolvía a Palma también cubría a la precaria autoconciencia nacional, República de escasos ciudadanos y de casi inexistentes lectores, a pesar de su relativo incremento en Lima y algunos otros núcleos urbanos del país fruto de la relativa expansión de la educación. Nuestro escritor - quien en 1851 publicó lo que podría definirse como el primer esbozo de lo que serían después sus tradiciones, titulado "Consolación. Página de una historia del alma” (Díaz Falconí, 2005)-, proyectó su figura sobre la nación en ciernes y contribuyó a darle existencia. Desde entonces, Palma se iría convirtiendo en el gran escritor que ahora conocemos y homenajeamos.

A diferencia del escritor europeo, burgués que combatía a la burguesía, Palma era un desclasado en un sentido totalmente diferente: proveniente de la plebe buscó su legitimación como escritor en las élites, en una sociedad en la que no habían calado los fundamentos del Iluminismo como en el Viejo Continente, en donde sí constituyó la argamasa de ideas que formó al ciudadano. Por el contrario, en una sociedad como la peruana signada por relaciones sociales arcaicas y escaso número de lectores, era inevitable que pervivieran ideas premodernas que obstaculizaran tanto la conformación del Estado nacional como la del ciudadano pleno. En tal tipo de configuración social, Palma debió labrar su reconocimiento en las esferas institucionales, aunque fue mucho más allá al buscar al mismo tiempo la legitimidad social introduciendo en las esferas 
privilegiadas las experiencias y formas de hablar de las clases populares. Se puede decir que Palma fue el caballo de Troya cultural por cuyo medio los iletrados se fueron incorporando en el imaginario nacional.

\section{Palma y la herencia de los ideólogos}

El proceso de Palma en su conversión como gran escritor ocurrió en un transcurrir intelectual y político del Perú que había sido hegemonizado por los ideólogos, incluso desde antes de la consecución de la Independencia. En efecto, figuras como Luna Pizarro, Sánchez Carrión, Vigil, Herrera, los hermanos Gálvez, y muchos otros, marcaron el ritmo y el contenido de los debates en el país. Laicos o sacerdotes, hombres de fe o no, radicales, conservadores o reformistas, lo cierto es que influyeron con distinta suerte en la vida política y en el propio manejo del Estado, llegando incluso a establecer su impronta en diversas cartas constitucionales, según su postura política.

Ideológicamente, Palma fue liberal (Pérez Garay, 2010), pero, a diferencia de la experiencia de desencantamiento europea, lo fue al interior de una sociedad mayoritariamente religiosa. El paso de lo celestial a lo terrenal no significó una ruptura definitiva con la manera anterior de mirar al mundo, por lo que Palma debió interpretar su papel como intelectual en un medio en el que, sin renunciar a su filiación liberal, recogió el sentimiento y prácticas sociales religiosas aunque no las compartiera. Después de todo, debemos recordar, el tradicionista había sido discípulo de Bartolomé Herrera en el Convictorio de San Carlos. Palma estampó en sus tradiciones la experiencia religiosa colonial, aunque ello no fue obstáculo para formular severas críticas a las instituciones clericales y a ciertas interpretaciones que hacían de nuestra historia algunos hombres de iglesia, como las del padre jesuita Ricardo Cappa (Gonzales Alvarado, 2019). 
Durante todo el siglo XIX, las letras nacionales habían ido labrando su camino y encontrando su identidad republicana. Incluso, para muchos no había propiamente una literatura nacional, solo una extensión de la literatura española. Así, la escritura literaria acompañaba en su devenir a la naciente República peruana, sus tanteos también eran los del propio país. Es cierto que Manuel Ascencio Segura y Felipe Pardo y Aliaga, por ejemplo, ya habían sembrado las primeras semillas de la literatura peruana, pero sus esfuerzos dieron frutos parciales al no definir una propuesta cabal de literatura nacional. Como destaca Oswaldo Holguín Callo al señalar el propósito que se impuso el propio escritor:

su obra $[\ldots]$ tiene el sentido de una literatura fundacional, pues en más de un sentido - cronológica y espiritualmente'funda' la producción literaria peruana al darle, en efecto, un carácter no sólo peculiar sino propio, un sentido, una identidad. Palma buscó empeñosamente ese resultado pues, desde muy joven, entendió que estaba haciendo obra nacional (Holguín Callo, s/f).

En este empeño, y por medio de sus tradiciones, Palma fue construyendo estereotipos de los diversos personajes de la vida social y política peruana, como el político, el militar, el funcionario, el cura o el comerciante, por ejemplo. A esto nos ayuda el libro póstumo que dejó inconcluso en las gavetas de su escritorio el estudioso Miguel Ángel Rodríguez Rea y que acaba de ser publicado por la Editorial Universitaria de la Universidad Ricardo Palma: Diccionario personal de Ricardo Palma (2019). En todos los casos, el autor nos arranca una sonrisa corroyendo simbólicamente una sociedad y sus actores superficialmente solemnes. He aquí a un Palma que usa el humor como instrumento de subversión cultural, de disolución de jerarquías, de trastorno de las convenciones. 
Por otra parte, la historiografía también estaba inmersa en el esfuerzo por la construcción de las bases nacionales para interpretar el pasado: ¿desde dónde leerlo?, ¿sobre quiénes hacer recaer las responsabilidades de los fracasos o la virtud de los aciertos?, ¿cómo se ha constituido nuestra genealogía nacional?, ¿qué narración es posible construir?, ¿quiénes serían los encargados de hacerlo?, entre otras, fueron las preguntas que trataba de ir respondiendo la naciente disciplina. Es posible adelantar que aun ahora no ha logrado contestar a estas y otras preguntas al interior de una narración legitimada.

\section{Auditorio, palabra escrita y palabra hablada}

Como es fácil colegir, las fronteras entre las disciplinas eran difusas en nuestra naciente República. Para ser más específico, no había distinción entre la literatura y la historia, además, era una sociedad mayoritariamente iletrada, y los que habían recibido instrucción no eran apegados necesariamente a la lectura y a la escritura. Paradójicamente, se experimenta una expansión de la palabra impresa, especialmente por medio del periodismo, que cumplió el papel de formar e informar a la minoría de ciudadanos existentes. Palma ocupó brillantemente los espacios del periodismo (Holguín, 2001, pp. 13-26) desde el cual fue definiendo el público al cual quería dirigirse e influir, y esto es una preocupación general de los intelectuales. Como apunta Lewis A. Coser: "los intelectuales necesitan un auditorio, un círculo de personas a las cuales pueden dirigirse y que pueden otorgarles reconocimiento" (1966, p. 19).

Paralela y complementariamente, la palabra hablada era fundamental para transmitir no solo información y conocimiento, sino también para reforzar o dar forma al sentido común y para divulgar lo que la palabra impresa había plasmado en el papel. Entonces, quien poseía el conocimiento 
y la pericia de la palabra escrita se colocaba en una situación privilegiada, y ese sujeto social privilegiado era, por lo común, en el contexto rápidamente esbozado, el escritor. Ahí destaca la figura de Palma.

De manera original, don Ricardo utiliza para su escritura la sonoridad de la palabra hablada (en frases o refranes, por ejemplo) proveniente del pueblo. Pocos textos literarios han llegado a las multitudes por medio de la oralidad como las Tradiciones. Pero Palma también era consciente de que no bastaba recoger la sabiduría popular, sabía que a ella había que dotarla de forma y calidad literarias, como le explica al historiador y político argentino Juan María Gutiérrez en carta fechada en Lima, el 5 de julio de 1875 (Palma, 2005, pp. 117-118). En ella hace explícita su manera de entender la creación de las tradiciones: la forma es fundamental, la escritura debe ser ligera y sin exagerar en los detalles, la conseja debe ser implícita sin que el autor tenga necesidad de decirla. Palma es muy sincero en la consideración de su propia obra: "Para mí, una tradición no es un trabajo ligero, sino una obra de arte", le escribiría al poeta español Vicente Barrantes desde Lima el 29 de enero de 1890 (Palma, 2005, p. 400).

Así, la tradición revela el origen y significado de la cultura oral popular, que es lo que hace destacar a Palma como un estudioso de la oralidad, lo que se puede corroborar en sus libros Papeletas lexicográficas o Neologismos. Con los más de 350 peruanismos que había recogido de nuestra habla, viajó en 1892 a España con motivo del cuarto centenario colombino con el objetivo de que la Academia Española los incorporara al Diccionario. Pero por más empeño que puso en las sesiones respectivas sustentando su propósito no encontró mucha aceptación en los académicos, lo que produjo amargura y desazón en nuestro escritor. En su Papeletas lexicográficas, de 1903, Palma aprovecha la ocasión para explicar su forma de trabajar: 
Tengo (entre otras, seguramente) la inofensiva chifladura de que cuando encuentro una palabra, en la conversación o en mis lecturas, que me parece necesaria o apropiada, y que no se halla en el Diccionario, sin pérdida de minuto la consigno en mi cartera de apuntes, para después estudiarla y alambicarla. Tal es el origen de este librito, para el que he puesto a contribución también, entre otros americanos aficionados a la Lexicografía castellana... (Palma, s/f).

Para Palma, universalizar nuestra manera de hablar era parte de nuestra nacionalización cultural. Reconocía que amaba a España, pero que más amaba a su patria: el nacionalismo político se fundamentaba en el nacionalismo cultural-literario.

\section{Los secretos de las Tradiciones peruanas}

Los relatos de ficción, las Tradiciones peruanas, dialogan con hechos históricos, los cuales, aconseja, deben ir al inicio da cada relato. La historia le significa una "liberación" de la actualidad. Así se lo confiesa al propio Juan María Gutiérrez en líneas escritas desde Lima el 12 de enero de 1875, en las que revela que se siente más a gusto desempolvando documentos viejos: "La conciencia me dice que acaso hago en esto un servicio a mi país" (2005, p. 111 ), concluye.

El presente le hastía a Palma, según su propia expresión; le cansa y molesta, podemos colegir. Por ello se interna en el pasado, pudiéndose entender también que quiere dejar atrás su azarosa vida como político, pero no lo hace como una renuncia a seguir actuando en el presente, sino que decide hacerlo desde otro ámbito, el de la creación literaria nutriéndola de hechos históricos. Julio Ortega describe bien la estrategia de Palma:

El discurso de la historia es incorporado por el discurso de la narración. La 'tradición' es, en todo sentido, la transición 
de los discursos; la ida y vuelta entre la fábula y la historia, entre el pasado y el presente, entre la experiencia y la conciencia, entre los paradigmas fabulosos y las secuencias históricas, entre la oralidad y la escritura, entre el saber común y el conocer crítico, entre la sabiduría popular y la ironía moderna, entre la cultura como tradición y la nación como identidad [...]. Desplazada siempre en esa condición mediadora, intermediaria, la 'tradición' promedia también entre los nuevos discursos latinoamericanos. En ese sentido, es un género, otra vez, intergenérico; un híbrido producto intertextual (Ortega, 1996, p. XXV).

Palma fabula, es cierto, pero partiendo de hechos históricos.

Nuestro escritor establece un elemento sustancial para comprender la tradición: que es relato popular, tal como le manifiesta en carta personal a Alberto Larco Herrera desde Lima el 26 de febrero de 1907, en la que reflexiona sobre su papel como escritor que anuda tradición, pueblo e historia (2006, pp. 37-38).

Palma no es un historiador profesional, es decir, no tiene pretensiones de decir la verdad, es más, revela que parte de la mentira (popular), pero releva algo muy interesante de su afán en tanto escritor-intelectual: ser intérprete de las multitudes. Palma, partiendo del saber popular ilustra a las élites, reconoce la autoridad del pueblo y él mismo emerge como un autor único. Así se lo dice en carta desde Lima el 18 de enero de 1878 al poeta chileno Carlos Toribio Robinet: "Mis tradiciones, más que mías, son de ese cronista que se llama el pueblo" (2005, p. 141). Nuestro tradicionista dice que él solo las "viste", es decir, que les da forma literaria: "Yo no invento, copio. Soy un pintor que restaura y da colorido a cuadros del pasado” (2005, p. 141).

Con las uniones de estos espacios y productos culturales, Palma teje las bases de su importancia como escritor que busca expresar 
a la nación. Si bien fue miembro del Partido Demócrata fundado por su amigo de muchos años, Nicolás de Piérola, se alejó de aquel a medida que prolongaba su ejercicio en el cargo público de director de la Biblioteca Nacional. ${ }^{1}$ Ello jugó a su favor en el sentido de no aparecer como representante de un grupo o facción políticos y en su legitimación como un escritor "nacional".

Los miembros de las élites ilustradas encontraban en Palma a un escritor que proporcionaba prestigio; los integrantes de la plebe se sentían reflejados en sus relatos que en buena parte partían de su propia experiencia e imaginario colectivo; los políticos no encontraban motivos para cuestionarlo, pues no lo identificaban como parte de alguna facción en disputa. Todo ello puede ayudar a explicar su longevidad como director de la Biblioteca Nacional en la que estuvo desde 1883 hasta 1912, es decir, 30 años. ${ }^{2}$

Cuando Palma asume la dirección de la Biblioteca Nacional del Perú contaba con 50 años y gran prestigio nacional e internacional como escritor, más aún, ya era el gran escritor de la aún joven República. En 1872 había publicado la primera serie de sus Tradiciones, a la que siguieron las de 1874, 1875 y 1877, como lo ha estudiado Alberto Varillas Montenegro, quien además afirma con acierto que: "Hacia 1870, el más importante de los escritores peruanos en el ejercicio de la profesión era Ricardo Palma" (2017, p. 27).

Desde la Biblioteca Nacional, Palma potenció su figura de escritor que encarnaba a la nacionalidad, y ello quizás no sea casual, pues dicha institución, fundada por el general José de San Martín el 28 de agosto de 1821, es la que preserva la

1 Sobre el papel de Ricardo Palma como funcionario véase Varillas Montenegro, 2016.

2 Para un vistazo de la experiencia de Palma en la Biblioteca Nacional puede consultarse el artículo de Pedro Guibovich Pérez (2018). 
memoria y la identidad nacionales. Su valor simbólico es, pues, muy importante. Haber asumido la conducción de la Biblioteca Nacional inmediatamente después de la derrota en la guerra con Chile, sacrificando un puesto importante en el extranjero, dedicarse con esmero y amor patriótico a su reconstrucción, solicitar o comprar libros para volver a llenar sus estantes, poner las salas de lectura nuevamente al servicio de los ciudadanos, fueron razones más que suficientes para pensar que él como máximo representante de la República de las letras encarnaba el orgullo y la dignidad de un país que también buscaba su reconstrucción. Desde ahí proyectó su influencia a las nuevas generaciones de escritores y de los sujetos de ideas en general.

\section{Palma y los jóvenes del 900}

Desde la perspectiva de las generaciones, la del 900 es la que espiritualmente se sintió más cercana al tradicionista Ricardo Palma. ${ }^{3}$ Fueron sus integrantes los que, luego de pasar el trago amargo de la Guerra del Pacífico, de ser espectadores de la violencia desatada en las guerras civiles de 1884 y de 1895, y de digerir las flamígeras acusaciones de Manuel González Prada en contra de la oligarquía dominante, erigieron a Palma como una figura ejemplar. Es usual establecer la vinculación del pensador ácrata con los jóvenes hasta el punto de casi invisibilizar las relaciones de Palma con la juventud, que sin embargo tuvo un contenido trascendental.

Una anécdota que revela la relación de Palma con los jóvenes es la siguiente. En 1905 cuando pensaba ya en el retiro, fatigado por los años, le pide a José de la Riva Agüero que le escriba a Francisco García Calderón, que radicaba en Francia,

3 En adelante, retomo algunas ideas y fragmentos que presenté en mi artículo sobre la vinculación de Palma con los novecentistas (2012), agregando más información y reflexiones. 
manifestándole que deseaba que lo sucediese como director de la Biblioteca Nacional con un sueldo de 300 soles, lo que permitiría volver al Perú al ya importante intelectual. Sin embargo, García Calderón, en carta desde París el 29 de febrero de 19054, rechaza el ofrecimiento prefiriendo continuar con su carrera diplomática; pero sobre todo pesó en él la razón de mantener independencia y distancia física del país para emitir sus opiniones sin restricciones, para ser un intelectual libre, lo que, pensaba, no podría ser si aceptara dicho encargo.

El original autor de las Tradiciones peruanas fue considerado por intelectuales como José Gálvez, José de la Riva Agüero, Víctor Andrés Belaunde, los hermanos Francisco y Ventura García Calderón y otros novecentistas, su maestro. El espíritu que trasuntaban sus creaciones literarias era más afín a ellos que los latigazos del pensador ácrata. Su predilección por el pasado, especialmente colonial, su liberalismo que lo colocaba en contra de las fracciones más obsoletas de las élites oligárquicas, su pierolismo con olor a multitudes y, no menos importante, su obra de reconstrucción de la Biblioteca Nacional, fueron las razones que permitieron establecer una comunicación directa entre el ya anciano literato y los jóvenes insurgentes del 900.

\section{José Gálvez Barrenechea: el heredero}

José Gálvez Barrenechea heredó la pluma de Palma, quien lo identificó como su más genuino heredero literario ${ }^{5}$. En 1915

4 Archivo del Instituto Riva Agüero de la Pontificia Universidad Católica del Perú.

5 El siguiente es tenor de la carta que Palma escribe a Gálvez: “Miraflores, 22 de Mayo 1913. Mi queridísimo poeta José Gálvez va a matricularse entre los hombres que viven la vida de la gente seria. Por eso le obsequio la pluma con que escribí mis TRADICIONES, a fin de que la entinte para dar a luz cuadros históricos-sociológicos de Lima. Por los pocos que ha publicado hasta ahora, puedo augurar que mi pluma, manejada por José Gálvez, enaltecerá siempre el 
sustentó su tesis Posibilidades de una genuina literatura nacional, en la que el hombre de letras es apreciado como el baluarte de las letras peruanas y quien le otorgaba su genio y carácter. En polémica con Riva Agüero - quien había sostenido que no puede haber literatura propiamente nacional porque somos provincia espiritual de España-, afirmaba que sí hay una literatura con rasgos específicos que permiten que se le llame peruana. Esas características, que dan forma al criollismo, son el tono gracioso, pícaro, festivo, cuyo máximo representante es Palma, precisamente, cúspide de un proceso que parte con Juan del Valle y Caviedes, Manuel Ascencio Segura, Felipe Pardo y Aliaga, entre otros.

Gálvez, también preocupado por retratar aspectos de la vida cotidiana como bases de la identidad colectiva nacional, compartía con sus compañeros generacionales la idea de la necesidad de echar a andar un conjunto de reformas tendientes a regenerar las bases de la reconstrucción nacional sin exacerbar los conflictos ya existentes. Los novecentistas en general estaban convencidos de que solo una élite ilustrada sería capaz de resolver las crisis del Perú para integrar en un cuerpo de nación a todos sus habitantes. A su propia manera, los jóvenes del 900 pretendían seguir las huellas nacionalistas del gran escritor Ricardo Palma.

El vínculo entre Palma y Gálvez es especial y no se compara con el que el maestro mantuvo con los otros novecentistas. Incluso, sería el viejo tradicionista quien, en 1917, incorporaría a Gálvez a la Academia Peruana de la Lengua. ${ }^{6}$

recuerdo de mi nombre. Ricardo Palma".

6 La Academia fue fundada en 1887, y su primer presidente fue Francisco García Calderón Landa, íntimo amigo de Palma y padre de los dos novecentistas. Quien lo sucedería en el cargo sería precisamente el tradicionista, quien en 1917 la reorganizaría, apoyado por la labor de los miembros de la generación del 900 . 
La confianza y cariño entre Gálvez y Palma se deja ver en la carta que aquel le envía desde Barcelona el 12 de octubre de 1918, en donde cumplía funciones de cónsul del Perú durante el segundo gobierno de José Pardo y Barreda. En esas líneas le recuerda a su maestro que es el Día de la Raza, "que para Ud. ha de tener recuerdos imborrables, por su admirable actuación en España, cuando la celebración del cuarto centenario del descubrimiento de América", ${ }^{7}$ en donde el gran escritor defendió la legitimidad de nuestra propia forma de hablar y escribir, como hemos visto.

\section{Víctor Andrés Belaunde, Julio C. Tello y Felipe Sassone: palabras de admiración y gratitud}

Por su parte, Belaunde -además de reconocerle a Palma su lugar principalísimo en el proceso literario peruano al calificarlo como "la gran figura de la literatura criolla" y de señalar que era un conspicuo lector de Voltaire - releva su papel en tanto intelectual: "Palma fue el caso de un literato puro. Hizo arte por el arte, sin ninguna mezcla de propósito ideológico, sin ninguna postura de conductor" (1931, p. 301). Pero posteriormente también rescataría la participación del escritor en los terrenos de la política, lo que resultaba inusual en ese tiempo, en el que solo se privilegiaba la actividad literaria de Palma (Belaunde, 1934).

Palma enlazaba a los novecentistas directamente con tradiciones y el pasado; con la nación y la cultura, pero no con la política. Mientras González Prada buscaba incorporar a los jóvenes por medio de la ideología y la acción política que sirvieran de palanca para la renovación integral del país, Palma se acercaba a ellos desde la literatura y la historia para consolidar la identidad nacional.

7 Archivo Ricardo Palma. Biblioteca Nacional del Perú. 
Otro miembro del 900 que gozó del cariño y admiración de Palma fue el fundador de la arqueología en el Perú: Julio C. Tello. Sigo a Holguín Callo (2001, pp. 149-153) en la historia que nos permite conocer la relación que existió entre ambos hombres de las letras y del saber.

Palma conoció a Tello desde sus tiempos de escolar, cuando era condiscípulo de su hijo mayor, Ricardo. Reconociendo la inteligencia del joven estudiante, actuó como su protector haciendo que lo promovieran a auxiliar en la Biblioteca Nacional en donde ya laboraba; posteriormente lo ascendió a oficial conservador alentándolo a que sea un "gran bibliófilo". Por su parte, y en reciprocidad afectuosa, Tello le dedicaría su tesis de 1908 en medicina agradeciendo su "ejemplo y consejos". En 1909, Palma lo presenta en sociedad en reunión realizada en el Parque Zoológico colocándolo a la altura de Riva Agüero y Francisco García Calderón, "las tres lumbreras" de la nueva generación, según sus propias palabras. El cariño y respeto intelectual que sentía el escritor por el futuro arqueólogo se hace patente en sendas cartas que envía a colegas extranjeros llenándolo de elogios. Tello nunca olvidaría el apoyo que recibió de su protector.

Hubo otro escritor del 900 apenas mencionado pero muy interesante que también expresaba su admiración por Palma. Me refiero a Felipe Sassone, dramaturgo que salió muy temprano del Perú, en el año 1905, hacia Europa, y terminaría por radicar en España. A pesar de su lejanía física del país, Sassone mantendría correspondencia con sus compañeros generacionales, y también con Palma. En misiva escrita en la propia Lima, en donde estaba de paso, el 2 de setiembre de 1913, le dice a su maestro: "soy limeño, D. Ricardo y soy artista, ipuede Ud. dudar de que le admiro y quiero?". Varios

8 Archivo Ricardo Palma. Biblioteca Nacional del Perú. 
años más tarde, en sus memorias tituladas La rueda de mi fortuna, de 1958, recordaría las imágenes que transmitían las Tradiciones "que había evocado con fábulas ciertas y sueños de su fantasía, que había creado, recreado, inventado, para regalo de nuestra bella historia, aquel cuentista y poeta, viejo limeño y mazamorrero que se llamó Ricardo Palma" (Sassone, 1958, pp. 104-105).

En una segunda carta de Sassone, ahora desde Madrid, 29 de marzo de 1915, este le expresa a Palma su gratitud por algunas palabras que ya le había enviado por medio de carta que lamentablemente no conocemos. Este aspecto cubre prácticamente toda la comunicación:

Ya no puede envanecerme la admiración de nadie, puesto que acabé. La muerte se llevó de mi casa el amor y se llevó también mi juventud y mi sueño de arte. Pero si para este he terminado, aún pueden caer como un bálsamo, las palabras buenas de consuelo y de piedad en la llaga viva de mi corazón, y las que Ud. me envía, con su mano de artífice que escribió tantas bellas páginas, así como estas obligáronme á la admiración, me obligan para siempre a tenerle gratitud y cariño. ${ }^{9}$

A pesar de la distancia, Sassone mantuvo en vigencia la admiración que tenía por Palma.

\section{José de la Riva Agüero y el "benigno brujo"}

Por otra parte, Riva Agüero, que conocía desde que era niño a Palma gracias a una visita a la Biblioteca Nacional, describiría al maestro como un "benigno brujo" que traía la historia al

9 Archivo Ricardo Palma. Biblioteca Nacional del Perú. 
presente, que revivía a los héroes muertos con sus relatos "y que nos hacía contemporáneos de lo pasado". El entonces director de la Biblioteca Nacional, dada la curiosidad del precoz interlocutor por los retratos de personajes peruanos y los cuadros de Francisco Lazo, "se los enseñó y explicó, respondiendo con indulgencia a las incesantes preguntas de mi vivacidad infantil [...] Mi ingenua mirada de niño lo situó en su exacto medio espiritual, presintiendo de golpe la serie íntegra de sus Tradiciones" (Riva Agüero, 1962, pp. 396).

Pero lo más trascendental es que en su tesis de 1905, Carácter de la literatura del Perú independiente, Riva Agüero ubica al tradicionista en el eje de nuestra creación literaria de manera por demás expresiva al señalar que

es el tipo del criollo culto, literario [...] Palma es el representante más genuino del carácter peruano, es el escritor representativo de nuestros criollos [...] príncipe de la literatura patria $[\ldots]$ por el hecho de haber creado un nuevo género, por el número y la calidad de sus escritos y por la difusión de su fama, obscurece y eclipsa a casi todos los que hasta aquí llevo examinados (1905, pp. 180).

Bajo estas consideraciones se comprende mejor el tono amistoso de sus cartas.

En carta que Riva Agüero envía a Palma desde Vichy el 23 de noviembre de 1913, no solo deja ver su admiración por el gran escritor sino que también nos revela la fama de este:

A los pocos días de encontrarme en ese balneario, conocí en el teatro a un académico americano, que naturalmente, al saber que yo era del Perú, me habló de Ud. y me pidió noticias de la salud, de sus últimos escritos y de su salida de la Biblioteca: era el costarricense Marqués de Peralta, 
ministro plenipotenciario de su país en Europa, que conoció a Ud. en España cuando las fiestas del centenario de Colón. Cumplo con enviarle a Ud. los saludos que me encargó y las felicitaciones que agregó al saber detalles de las causas de la separación de Ud. de la Biblioteca y de las manifestaciones de apoteosis que la acompañaron. ${ }^{10}$

En nueva carta, esta vez enviada desde París el 15 de julio de 1914, Riva Agüero felicita a su corresponsal por su nombramiento como Director Honorario de la Biblioteca Nacional, luego de caído el gobierno de Guillermo E. Billinghurst (1912-1914), quien había nombrado a González Prada como el nuevo director de dicha institución, cargo al que renunciaría luego del golpe de Estado comandado por Óscar R. Benavides:

De vuelta de Madrid, en donde me han servido mucho las recomendaciones que tuvo Ud. la bondad de darme, me he encontrado en los periódicos atrasados de Lima, que aquí he leído, con la muy agradable noticia del nombramiento de Ud. como Director Honorario y Consultor Técnico de la Biblioteca Nacional. Le doy á Ud. mi más afectuoso enhorabuena; y se la doy ante todo al Gobierno y al país por este acto de reparación de la irritante injusticia cometida con Ud. hace dos años [hacia fines del primer gobierno de Augusto B. Leguía, en 1912]; y me complace infinito este nuevo y tan merecido homenaje á Ud. El restaurador de la Biblioteca, el glorioso patriarca de la literatura nacional, la primera personalidad intelectual del Perú, recibe con esta medida completo desagravio de la torpeza de 1912; y tendrá que reconocer que a pesar de las ceguedades de la política y las envidias que toda superioridad despierta, al cabo en nuestro país la razón y la gratitud se abren paso, y colocan ó restablecen á cada cual en el lugar que le corresponde en el

10 Archivo Ricardo Palma. Biblioteca Nacional del Perú. 
aprecio público. Y Ud. venerado maestro sabe por pruebas inequívocas, que es el de Ud. el primero. ${ }^{11}$

En la tesis de 1905 ya mencionada, Riva Agüero había establecido comparación entre Palma y Walter Scott, creador de la novela histórica, juicio que cuestiona Francisco García Calderón al señalar que:

Si de Walter Scott se ha podido escribir que tenía el alma feudal, no creo que Palma tenga alma colonial. Ha vivido mucho, con el amor y con el espíritu, en el signo de la Enciclopedia; ha llegado a ser ingenuo por refinamiento, colonial, por simpatía de anticuario" (1979, p. 49).

De alguna manera, García Calderón anticipa el argumento de centenaristas como Mariátegui y Haya de la Torre sobre Palma, que se oponían a la lectura conservadora que consideraba al tradicionista colonialista y, por ende, pasadista.

En un texto contemporáneo, Manuel Pantigoso Pecero también embate contra dicha "imagen distorsionada" cuando afirma que nuestro escritor "lejos de sentirse un conservador, se consideraba más bien un liberal de antigua data, un progresista a carta cabal y, además, una persona que amaba profundamente a su patria. Y todo ello lo podía demostrar" (2017, p. 287).

\section{Ventura García Calderón: antologador de Palma}

El hermano de Francisco García Calderón, Ventura, confesaría que Palma atraía a él y a sus compañeros generacionales con sus piezas literarias llenas de simpatía y de buen sentido del humor, que eludían el presente oprobioso. Afirmaba que la tradición, "como todas las cosas ingeniosas y volátiles no cabe en el

11 Archivo Ricardo Palma. Biblioteca Nacional del Perú. 
casillero de una definición", relevando la creatividad del escritor. A diferencia de Riva Agüero, y en coincidencia con su hermano Francisco, recomienda no buscar en Palma la ascendencia de Scott en sus ficciones literarias. Pero lo fundamental del juicio de Ventura se encuentra en su libro de 1910, Del romanticismo al modernismo, donde sentencia: "lo más nacional, lo más original también de esta vena criolla, es la $\square$ tradición $\square$ de Ricardo Palma" (1910, p. XV).

Conocemos dos cartas de Ventura a Palma. La primera aparece sin fecha, aunque por su contenido se entiende que había habido comunicaciones previas. Ventura le agradece en primer lugar por el pésame que le hizo llegar por la muerte de su hermano José en la Batalla de Verdún -ocurrida el 5 de mayo de 1916-, defendiendo a Francia en contra de la invasión alemana durante la Gran Guerra (1914-1918) ${ }^{12}$. Luego le comunica a su corresponsal que la Casa Maucci lo ha contratado como director de la Colección de Grandes Escritores Americanos, que se haría famosísima y se convertiría en fuente de consulta permanente para los críticos y creadores literarios. Y desde ese cargo le informa que tiene planeado editar un tomo llamado Las mejores tradiciones de Ricardo Palma, a la vez que le consulta si lo autoriza a publicar la selección que ha confeccionado. También es necesario señalar que luego de esa oportunidad Ventura antologaría por lo menos dos veces más al anciano autor.

En las líneas siguientes, Ventura le ruega a Palma que conteste al "cuestionario mundial" que está llevando a cabo con un colaborador francés (no menciona quien). Las preguntas - que incorpora en la carta de París, 15 de noviembre de 1916giran alrededor tanto de sus datos biográficos, de su opinión sobre los comentarios que el propio Ventura hizo de su obra, especialmente en Del romanticismo al modernismo de 1910 y La

12 Archivo Ricardo Palma. Biblioteca Nacional del Perú. 
literatura peruana de 1914, libros en los que básicamente revalora las Tradiciones, pero sin dejar de señalar que son ficciones a partir de ciertos jalones de historia. Además, le solicita que le envíe algunas de sus publicaciones.

En siguiente carta (París, 9 de febrero de 1917), y ya con membrete "Colección de Grandes Escritores Americanos" dirigida por Ventura García Calderón, le agradece a Palma su respuesta a las preguntas realizadas. A pesar de sus temores de que sus preguntas quedaran sin responder (por lo que Ventura enviaba constantes cables por telégrafo), el tradicionista cumplió con su pedido. Pero lo más importante es la felicitación por el interés del dramaturgo español Eduardo Marquina en escribir un drama a partir de una de las famosas tradiciones:

Estoy seguro de que, después de él, muchos irán por temas a ese venero inagotable. Cuando se estrene la obra en Madrid, trataré de pegar un salto allí y como mi amigo Gómez Carrillo es director de El Liberal y mi amigo Ciges Aparicio es director de El Imparcial, organizaremos un repique o como dirían en Madrid un jaleo, en honor de nuestro admirado decano. ${ }^{13}$

\section{El legado de Palma y los novecentistas}

Los jóvenes novecentistas, como hemos podido corroborar, se sintieron intelectual y sentimentalmente cercanos a Ricardo Palma. Una manifestación de ello fue el homenaje que realizaron en su honor cuando el gobierno de Leguía lo desembarcó de la dirección de la Biblioteca Nacional. En efecto, el lunes 11 de marzo, en el Teatro Municipal, se realizó la velada de desagravio, en la que Riva Agüero afirmaría: "sin hipérbole alguna y pesando cuidadosamente las palabras, se os debe

13 Archivo Ricardo Palma. Biblioteca Nacional del Perú. 
proclamar uno de los más principales y eficaces agentes en la formación del sentimiento de nuestra nacionalidad" (1962, p. 60). Posteriormente, con motivo del fallecimiento del escritor, ocurrida el 6 de octubre de 1919, los novecentistas le dedicaron un número de la revista Mercurio Peruano, fundada por Belaunde en 1918. La huella dejada por Palma en ellos permanecería a lo largo de sus vidas.

El periodista y poeta Luis Fernán Cisneros, novecentista también, caracterizado por la picardía que imprimía en sus escritos, resumiría el legado de Palma con las siguientes palabras:

Poeta infantil y romántico, primero, epigramático y satírico más tarde, jugó con sus aptitudes como quiso, hasta encauzarlas todas en el camino de la Tradición maravillosa. Podrá deberle el Perú la labor paciente de la reconstrucción de la Biblioteca Nacional y podrán agradecerle los jóvenes de hoy la serena austeridad de su vejez, deslizada mansamente en medio de emocionados anticipos de la inmortalidad; pero lo que no le pagará la patria nunca, porque es gloria que ni los héroes suelen darla, es la sonoridad de su nombre y el rendimiento universal a su memoria (1919, p. 261).

Con seguridad, podremos encontrar más evidencias de la admiración y afecto que sentían los intelectuales novecentistas por don Ricardo. Los casos mostrados nos revelan que los novecentistas consideraban a Palma como la referencia central del proceso literario nacional, encarnación de lo que llamaba en aquellos años de principios del siglo XX el "alma nacional". Su admiración no decayó con el tiempo. En conmemoración del primer centenario del nacimiento de Palma, los para entonces ya maduros novecentistas, en un país profundamente cambiado, le rindieron un homenaje final publicando sendos artículos en el libro titulado simplemente Ricardo Palma (1833-1933), editado por la Sociedad Amigos de Palma en 1934. 
Los novecentistas fueron prolíficos en sus referencias positivas sobre Palma. La relación personal que establecieron con él permitió que sus evaluaciones de la obra de nuestro gran escritor trascendieran al plano afectivo. No tuvieron a Palma como un pensador o ideólogo; pero sí reconocieron en él al gran escritor que encarnaba lo mejor de una nacionalidad que buscaba alcanzar su realización.

\section{Bibliografía}

Belaunde, V. A. (1931). La realidad nacional. (En torno al libro de Mariátegui). París: Le Livre Libre.

(1934). "Palma político". En VV. AA. Ricardo Palma (1833-1933). Lima: Sociedad Amigos de Palma.

Bénichou, P. (1981). La coronación del escritor, 1750-1830. Ensayo sobre el advenimiento de un poder espiritual laico en la Francia moderna. México: Fondo de Cultura Económica.

Cisneros, L. F. (1919). "El tradicionista Ricardo Palma”. En Mercurio Peruano. Revista mensual de ciencias sociales y letras. Lima, octubrenoviembre, núms. 16-17, año II, vol. III

Coser, L. A. (1966). Hombres de ideas. El punto de vista de un sociólogo. México DF: Fondo de Cultura Económica

Darnton, R. (2008). Los best sellers prohibidos en Francia antes de la Revolución. México DF: Fondo de Cultura Económica.

Díaz Falconí, J. (2005). Cronología de las Tradiciones Peruanas. Lima: Universidad Ricardo Palma,

Gálvez Barrenechea, J. (1959). Posibilidad de una genuina literatura nacional: el peruanismo literario. Lima: Casa Editora M. Moral 
García Calderón, F. (1979). Las democracias latinas en América. Caracas: Biblioteca Ayacucho

García Calderón, V. (1910). Del romanticismo al modernismo. París: Sociedad de Ediciones Literarias y artísticas.

Gonzales Alvarado, O. (2019). "Palma, Ricardo". En Religions of the World. Encyclopedia of Latin American Religions. Springer Nature. En https://www.springer.com/de/authors-editors/book-authors-editors/ springertoken-request-for-springer-authors/4090. Consulta:

(2012). "Ricardo Palma y el Novecientos. Retazos de reconstrucción epistolar”. En Yuyaykusun, núm. 5, Lima, Universidad Ricardo Palma. Versión digital en http://revistas.urp.edu.pe/index.php/ Yuyaykusun/issue/view/16

Guibovich Pérez, P. M. (2018). “Un verdadero templo alzado al saber humano: Ricardo Palma y la Biblioteca Nacional del Perú”. En Carlos Aguirre y Ricardo D. Salvatore (eds.). Bibliotecas y cultura letrada en América Latina. Siglos XIX y XX. Lima: Pontificia Universidad Católica del Perú.

Holguín Callo, O. (2001). Páginas sobre Ricardo Palma. Lima: Universidad Ricardo Palma.

(s/f). "Apunte biobibliográfico de Ricardo Palma". En Biblioteca Cervantes Virtual Miguel Cervantes: http://www. cervantesvirtual.com/portales/ricardo_palma/apunte_biobibliografico/ Consulta: 25 de setiembre de 2019.

Ortega, J. (1996). "Para una relectura crítica de Palma”. En Ricardo Palma, Tradiciones peruanas. Francia: Edición crítica, Edusp.

Palma, R. (s/f). Papeletas lexicográficas. Biblioteca Virtual Miguel Cervantes: http://www.cervantesvirtual.com/obra-visor/papeletas- 
lexicograficas--0/html/0 1c25 134-82b2-1 ldf-acc7-002185ce6064_2. html Consulta: 20 de setiembre de 2019.

(2005). Epistolario general (1846-1891). Lima: Universidad

Ricardo Palma

(2006). Epistolario general (1892-1904). Lima: Universidad

Ricardo Palma

Pantigoso Pecero, M. (2017). "Ricardo Palma, el Bibliotecario mendigo: amor al libro a través de sus cartas”. Aula Palma vol. XVI, núm. XVII, Revista del Instituto Ricardo Palma.

Pérez Garay, C. A. (2010). Liberalismo criollo. Ricardo Palma, ideología y politica (1833-1919). Lima: Universidad Ricardo Palma

Riva Agüero, J. de la. (1905). Carácter de la literatura del Perú independiente. Lima: Editora Rosay.

(1962a). "Homenaje centenario a D. Ricardo Palma".

En Estudios de literatura peruana: Del Inca Garcilaso a Eguren. Lima: Pontificia Universidad Católica del Perú.

(1962b). "La gran velada en honor de D. Ricardo Palma".

En Estudios de literatura peruana: Del Inca Garcilaso a Eguren. Lima: Pontificia Universidad Católica del Perú .

Rodríguez Guerrero-Strachan, S. (2008). "Figuras del escritor poscolonial". En En torno a los márgenes. Ensayos de lectura poscolonial. Colección Anejos de Cuadernos del Minotauro: Madrid: Ediciones Minotauro digital.

Rodríguez Rea, M. (2019). Diccionario personal de Ricardo Palma. Frases, citas y personajes en las Tradiciones Peruanas. Lima: Universidad Ricardo Palma 
Torres Puga, G. (2000). Historia de la literatura mexicana desde sus orígenes hasta nuestros días. México DF: Siglo XXI editores.

Varillas Montenegro, A. (2017). "Ediciones de las tradiciones de Palma". En Aula Palma vol. XVI, núm. XVII, Revista del Instituto Ricardo Palma.

(2016). "Ricardo Palma, correcto funcionario público". En Aula Palma vol. XV, núm. XV, Revista del Instituto Ricardo Palma.

Recibido el 12 de octubre de 2019 Aceptado el 29 de octubre de 2019 